- Most patients requiring oral surgical care may be safely and appropriately treated in the primary health care setting.

- There is a real risk of the broad clinical remit of oral surgery provision in the primary health care setting being restricted.

- Working as a team with adequate funding, dentists with special interests and specialists in oral surgery can improve the access of patients to specialist care.

\title{
An audit of 600 referrals to a primary care based oral surgery service
}

\author{
G. Bell ${ }^{1}$
}

\begin{abstract}
Aim To identify potential problems in the quality of care when oral surgery is provided in the primary health care setting.

Method Retrospective analysis of referral patterns, waiting times, treatment with clinical and histological diagnosis, including complications of 600 patients referred to a practice-based oral surgical referral service.

Results Fifty-three patients were not treated. Seventy-nine percent of patients were treated within four weeks of referral. The most common procedure performed was surgical removal of impacted third molar teeth. The most frequently observed complications were dry socket ( $n=31 / 703)$, pain and inflammation associated with resorbable sutures ( $n=11 / 453)$, and post-operative infection $(n=9 / 547)$. One patient with post-operative infection required care in the acute hospital setting.
\end{abstract}

Conclusion Acknowledging the small sample, it was safe and effective to diagnose and treat a broad spectrum of patients and oral surgical problems in the primary health care setting.

\section{INTRODUCTION}

In the United Kingdom since 1995, there have been developments to formalise the provision of specialist dental care in the primary healthcare sector. This began following the report of the Chief Dental Officer for England (CDO), who at the request of the Secretary of State for Health (UK) reviewed the arrangements for specialist training in dentistry. ${ }^{1}$ This review had been prompted following the report of the Chief Medical Officer (CMO) on specialist training in the light of European Directives, and the decision of the General Dental Council (GDC) three years earlier to propose specialist titles

\footnotetext{
'Specialist in Oral Surgery, Oakdale Cottage, Hawksdale, Dalston,

Carlisle, Cumbria, CA5 7BX

Correspondence to: Mr Garmon Bell

Email: garmonbell@tiscali.co.uk
}

Online article number E6

Refereed Paper - accepted 15 September 2006

DOI: $10.1038 /$ bdj.2007.571

${ }^{\circ}$ British Dental Journal 2007; 203: E6 in an effort to protect the public from unwarranted claims of specialisation..$^{2-4}$ Within his report, which supported many of the CMO's recommendations, the CDO upon reviewing European Directives in addition recommended the increased provision of specialist dental care in the primary healthcare setting, which was already well established within mainland Europe., ${ }^{5,6}$ The formal acknowledgement of such provision of care was new for the UK, but not the international scene where such practice had been taking place successfully for many decades, particularly in North America and Australasia. A few referral practices had, however, become established in the UK during the decade before the CDO's report, but their clinical remit was and is restricted by National Health Service (NHS) contractual arrangements, limited funding and lack of hospital admitting rights.

In 1996 the GDC, upon the request of the CDO, established the Specialist List Group, which was to confirm arrangements for training and registration. In 1998 the GDC established a list of domestic specialities, one of which was surgical dentistry, the aim of which was to provide a high standard of oral surgical care in the high street setting. ${ }^{7,8}$ However, in the intervening years, despite the speciality of surgical dentistry being the second largest list held by the GDC, there was very limited development in terms of training posts and appointment of specialists by healthcare authorities. The Department of Health had in the intervening period made several proposals relating to the improved delivery of healthcare, and increased utilisation of the primary healthcare sector. ${ }^{9-11}$ Based on these proposals, reports of patients experiencing difficulty of access to specialist dental care, and the continued discussion on the future of the surgical dental specialities, the Standing Dental Advisory Committee (SDAC) in 2003 requested the CDO to review the dental-based specialties. ${ }^{12}$ The review was undertaken and submitted in 2004, with one of the recommendations being to increase patient choice within proposals of the modernisation of primary care dentistry. ${ }^{13}$ In December 2005 the GDC, following through with the review, approved the recommendations of the Specialist List Review Group, one of 


\begin{tabular}{l|l}
$\begin{array}{l}\text { Table } \mathbf{1} \text { Reasons for patients not receiving surgery following } \\
\text { consultation }(\mathbf{n}=\mathbf{5 3})\end{array}$ & N \\
\hline Reasons why patients chose not to proceed to surgery & 14 \\
\hline Cost & 4 \\
\hline Symptoms had resolved & 2 \\
\hline Anxiety, declining sedation, referral for general anaesthesia & 3 \\
\hline Private medical insurance restricting care to that by an NHS consultant & N \\
\hline Reasons why surgeon chose not to proceed to surgery & 14 \\
\hline Apicectomy request with inadequate endodontic treatment & 1 \\
\hline Apicectomy request with obvious coronal microleakage & 2 \\
\hline Apicectomy request with root fracture & 1 \\
\hline Apicectomy request with excessive bone loss and mobility & 6 \\
\hline Pain of myofacial origin and not pericoronitis of third molar tooth & 1 \\
\hline Late incisor imbrication not due to impacted third molar teeth & 1 \\
\hline Medically unfit for surgery in primary care environment & 3 \\
\hline Symptoms resolved by simple restorative intervention & 1 \\
\hline Potentially malignant lesion referral forwarded to the hospital service &
\end{tabular}

which was the amalgamation of the specialties of surgical dentistry and oral surgery, with a reconfigured oral surgery specialty having a core clinical remit with an extended range of competencies fulfilling European Directives..$^{14,15}$ In April 2007 this came into effect.

This audit was conducted to identify problems in the delivery of oral surgical services in the primary healthcare setting, on the basis that such perceived difficulties were the reason why there had not been earlier and more formal development of specialist services.

\section{METHOD}

The audit covered 600 consecutive referrals to one registered specialist in oral surgery providing a referral service across North Cumbria (England) and a small portion of Dumfries and Galloway (Scotland). It had not been possible to obtain satisfactory terms of NHS provision, and the service was financed by patient payments on a private basis. A schedule of fees was available to all practitioners and patients.

For the purposes of audit the standards of care were set such that patients referred should be treated within a similar time period and with a complication rate no higher than that which would occur if the patient had been treated in the hospital setting, and that clinical decisions remain the same between dental practice and the hospital setting. The reason for choosing the provision of care in the secondary healthcare setting as the gold standard was that traditionally, oral surgical care was and is provided within this setting, although the different demographic and clinical features of patients treated in each setting have been acknowledged.

All patients were referred in writing, enclosing radiographs if appropriate, with an outline of the reason for referral. Most patients were seen pre-operatively for an assessment and following examination the treatment plan was discussed and confirmed. Patients who experienced difficulty attending for pre-assessment because of working away from home, or because of shortage of time between referral and treatment, were pre-assessed over the telephone. Patients were provided with information leaflets, and given a copy of the consent form, which included the procedure to be performed along with the benefits and potential risks and complications, confirming whether or not intravenous sedation was to be provided. After care was discussed and also included on the information leaflet, which was posted to those who could not attend for assessment with the exception of those for whom there was inadequate time between referral and treatment for the postal system to deliver.

The surgical team consisted of one surgeon, one trained dental nurse who acted as first assistant, and a second trained dental nurse who provided a supporting role and attended to the patients in the post-operative period. Pre-set sterilised surgical trays were used. Three basic trays were set up for surgical exodontia, endodontic surgery and soft tissue procedures. Clean, non-sterile surgical gloves were used, although an alcoholic surgical rub was used after donning gloves. Clean, non sterile, disposable drapes, and fine suction tips were used. All surfaces were cleaned with alcohol wipes between patients, and a barrier membrane used for high frequency contact surfaces. Straight hand-pieces with surgical fissure burs were used with sterile saline for irrigation. During endodontic procedures, magnification loupes (x4) were used, along with ultrasonic apical preparation and glass ionomer retrograde restorations. All patients had a pre-operative rinse of chlorhexidiene gluconate. Antibiotics were not prescribed routinely. Polyglactin resorbable suture materials were used when necessary.

When sedation was required all patients were given written and verbal information on the nature of conscious sedation, and the level of care necessary and precautions to be taken in the 24-hour post-operative period. Intravenous cannulae were used in all cases, along with pulse oximetry, and intermittent non-invasive blood pressure monitoring equipment. A separate recovery room, which had capacity for at least two patients and was adjacent to the treatment area, was used for all patients, with the second nurse providing appropriate care. All patients were seen by the surgeon before leaving the building and given written and verbal post-operative instructions. A contact telephone number was provided to all patients should post-operative complications arise. Review appointments were only arranged if deemed necessary.

Within a day following treatment a written summary was posted to the referring practitioner, and if appropriate the patient's general medical practitioner, outlining the indications for surgery and any particular points explained to the patient at the assessment appointment. Included in the letter was an indication of any particular follow-up that was required with the general dental practitioner.

When specimens were submitted for histopathological examination a summary along with a discussion of the implications was mailed to the referring practitioner once it became available. Patients were contacted by telephone if the histopathology report differed from the clinical diagnosis, or if they were anxious regarding the outcome of the report.

Where possible, the specialist who had provided the care saw patients with post-operative complications, and if this 
was not possible, then care was provided by the patient's general dental practitioner. A system of reporting complications was established.

\section{RESULTS}

Six hundred patients were referred from $60 \%(n=35 / 55)$ of the dental practices in North Cumbria and the adjoining portion of Dumfries and Galloway. Six patients were treated within 24 hours because of an acute problem, following a telephone call from the referring practitioner. Twenty percent $(n=120)$ of patients were treated within one week, with 79\% $(n=473)$ of patients seen and treated within four weeks of referral and $96 \%(n=576)$ within 10 weeks. The remainder of patients treated after 10 weeks choose to delay treatment for personal reasons. Ninety-nine patients, including those seen within 24 hours of referral because of acute severe symptoms, were treated without having been seen for pre-assessment. There was no change in the treatment plan for those patients that had been pre-assessed over the telephone, nor was there any increase in post-operative complications.

The ASA grade of patients referred was ASA 1 in 67\% (n $=404)$ of cases, ASA 2 in 29\% $(n=175)$, and ASA 3 in four percent $(n=21)$ of cases. ${ }^{16}$ Seven patients were taking warfarin medication, with no change being made to their medication for the purposes of treatment. A pre-operative International Normalised Ratio (INR) of bleeding time was obtained for these patients, and local haemostatic measures were applied. On the basis of general health only one patient was deemed unsuitable for treatment in the primary healthcare setting and passed onto the hospital service.

Following consultation 53 patients did not progress to receive treatment (Table 1). Feedback and advice was provided in writing when the specialist declined to treat.

Three hundred and ninety-two individual intravenous sedation procedures were provided, with no complications with the exception of one failure to complete treatment because of lack of patient co-operation. This particular patient subsequently accepted treatment under local anaesthesia alone, three days later.

The most frequently performed procedure was the removal of impacted third molar teeth (Tables 2-4), constituting 34\% (n $=241 / 703$ ) of all teeth removed. The most common post-operative complication was dry socket (Table 5), with an incidence of $4.4 \%(n=31 / 703)$. Seventy-seven percent $(n=24 / 31)$ of dry sockets observed in this audit arose following the removal of impacted mandibular third molar teeth, with $11 \%(n=24 / 221)$ of lower third molar removals resulting in a dry socket. Of the 453 patients who required resorbable sutures, 11 experienced pain and inflammation with the sutures presenting approximately seven to ten days post-operatively, and were pain free within 12 hours of removal of the sutures. The infection rate of patients undergoing treatment was $1.6 \%(n=9 / 547)$, with the highest incidence arising following the removal of impacted third molar teeth $(2.9 \% ; n=7 / 241)$. None of the soft tissue procedures became infected. One patient required hospital admission and intravenous antibiotic therapy because of a buccal space infection with pyrexia following simple elevation of an impacted mandibular third molar tooth with a history of pericoronitis. Within four hours of treatment, three patients received advice regarding post-operative pain control over the
Table 2 Types of operative procedures performed

\begin{tabular}{l|l}
\hline Procedure & N \\
\hline Removal of teeth & 703 \\
\hline Endodontic surgery & 88 \\
\hline Cyst enucleation & 5 \\
\hline Excision biopsy of lesion of oral mucosa/alveolus & 20 \\
\hline Incisional biopsy of lesion of oral mucosa & 1 \\
\hline Pre-prosthetic surgery - tuberosity reduction & 1 \\
\hline Periodontal surgery & 3 \\
\hline Closure of oro-antral communication/fistula & 2 \\
\hline Maxillary sinus wash-out & 1 \\
\hline Release of tongue tie & 1 \\
\hline
\end{tabular}

Table 3 Types of teeth removed during surgery

\begin{tabular}{|l|l|l|}
\hline Type of tooth removed & N & $\begin{array}{l}\text { Related to } \\
\text { maxillary sinus }\end{array}$ \\
\hline Upper third molars (impacted/unerupted) & 20 & 12 \\
\hline Upper molar teeth (excludes impacted 8s) & 145 & 32 \\
\hline Upper premolars (impacted/unerupted) & 3 & - \\
\hline Upper premolars & 62 & 7 \\
\hline Upper canine (impacted/unerupted) & 1 & - \\
\hline Upper canines & 21 & 3 \\
\hline Upper incisors & 16 & - \\
\hline Lower third molars (impacted/unerupted) & 221 & - \\
\hline Lower molars (excludes impacted 8s) & 125 & - \\
\hline Lower premolars (impacted/unerupted) & 1 & - \\
\hline Lower premolars & 53 & - \\
\hline Lower canines & 15 & - \\
\hline Lower incisors & 25 & - \\
\hline Compound odontome & 1 & - \\
\hline
\end{tabular}

telephone. None of the patients taking warfarin experienced post-operative haemorrhage (Table 5).

Excluding those patients seen with post-operative complications, review appointments were made for three patients. Five patients, rather than being seen for review, were followed up with a telephone call within a few days of the treatment. Three patients were telephoned with their histopathology reports, two because of anxiety over the report and one because of a difference between the clinical diagnosis and histopathological report.

\section{DISCUSSION}

Research has shown a high level of patient satisfaction when oral surgical care is provided within a primary care environment that is familiar to them. ${ }^{17}$ This service simplified the appointment process, with direct person to person contact 


\begin{tabular}{l|l}
\hline \multicolumn{2}{|l}{ Table 4 Histological diagnosis of specimens submitted } \\
\hline Diagnosis & N \\
\hline Fibro-epithelial polyp & 6 \\
\hline Haemangioma (lower lip) & 2 \\
\hline Mucocele & 3 \\
\hline Squamous papilloma & 2 \\
\hline Radicular/residual cyst & 4 \\
\hline Incisive canal cyst & 1 \\
\hline Granulation tissue (non-healing socket/peri-radicular) & 7 \\
\hline Foreign body granulomatous reaction (non-healing socket) & 1 \\
\hline
\end{tabular}

Table 5 Numbers of post-operative complications

\begin{tabular}{|l|l|}
\hline Complication & N \\
\hline Dry socket & 31 \\
\hline Inflammation and pain around sutures & 11 \\
\hline Post-operative infection & 9 \\
\hline Post-operative haemorrhage & 4 \\
\hline Anxiety because of immediate post-operative pain & 3 \\
\hline Temporary facial nerve palsy & 1 \\
\hline Inferior alveolar/lingual nerve injury & 0 \\
\hline Oro-antral fistula & 0 \\
\hline
\end{tabular}

between the referring dentist and the referral centre that was closest to the patient. Alternatively patients could travel to a referral centre further from their home to achieve a sooner appointment. In addition, referring dentists were able to give their patients a date for assessment and treatment while the patient was still in their surgery by simply telephoning one of the referral centres. A similar arrangement already exists in the NHS, known as patient focused booking, or choose and book, although the person to person contact does not always exist as in a practice setting, which also has the benefit of local and personal knowledge, and the patient receives an appointment for consultation only, not treatment also. Research undertaken within a specific geographic location demonstrated that a significant proportion of general dental practitioners were dissatisfied with their secondary care-based oral surgery provider because of length of waiting times, and the distance for patients to travel. ${ }^{18}$ This service kept waiting times to a minimum by arranging extra treatment sessions as necessary, and by utilising four separate geographical locations the service was available to patients at a location closer to their home.

Most patients were satisfied not to be reviewed unless necessary, supporting the findings of recent research and audit. ${ }^{19,20}$ Most patients were satisfied with only being contacted by telephone if the histopathological report differed from the clinical diagnosis.

The service did not involve the use of sterilised drapes, gowns or gloves, and with antibiotics not being prescribed routinely, the incidence of post-operative complications was no higher than previously reported from research involving the secondary health care sector, although demographic and clinical variables must be acknowledged. ${ }^{21-25}$ However, it was not possible to accurately compare the incidence of post-operative infection or wound inflammation with the secondary healthcare sector as clinical outcome data is not readily available from this setting for the majority of routine work performed. There is no proof that not using sterile gloves increases the incidence of post-operative complications and this audit would support that view. ${ }^{26-28}$ Results from a recent audit comparing practice-based surgical care that did not use sterile drapes, gowns or gloves with a hospital service that did, showed no increase in complication rates for the primary care setting. ${ }^{29}$ The decision not to use antibiotics was based on reliable clinical evidence that antibiotics do not influence the incidence of post-operative complications, namely infection. ${ }^{30,31}$ The decision to use a pre-operative rinse of chlorhexidiene gluconate was based on similar evidence. ${ }^{32,33}$ While it has been demonstrated that metronidazole may reduce the incidence of dry socket, ${ }^{34}$ the findings of several research papers do not show any reduction. ${ }^{25,35-37}$

The referrals in this audit relate mostly to the main disease processes that dentists treat on a regular basis, namely dental caries, gingival and periodontal disease, pulpal and periapical disease. To date surgical dental specialists working in the primary healthcare setting, particularly those relying on NHS funding have restricted most of their clinical activity to these three disease processes, and may have only cared for patients on a short term basis. However, the clinical remit of oral surgery is much broader than providing a tooth removal service. ${ }^{14,15}$ To enable oral surgery specialists to provide a comprehensive diagnostic, advice and treatment service in the primary healthcare setting, a considerable change in specialist and general practice philosophy is required. Specialist practitioners have the opportunity to accept responsibility for the medium to long term care of patients with a broad range of disease processes, in keeping with GDC guidelines and European Directives. $^{14,15}$ Specialist practitioners may request and act on the results of special investigations, such as radiological, biochemical, haematological, microbiological and immunological investigations, and liaise with general medical practitioners and other specialists, both medical and dental. Such clinical practice is common in most European countries, but not in the UK, because of the concept of such services having to be provided within the secondary healthcare setting. Such changes in primary care practice in the UK, with individual specialist practitioners working within their own level of competence, would require continuing audit and peer review to ensure that standards of care were being maintained. General dental practitioners working within their own level of competence and clinical remit already provide for long term care and liaise with general medical practitioners and hospital-based specialists as required. Specialist oral surgery practice providing medium to long term care for a broad range of disease processes would therefore only be a continuation of what is already being provided.

It is not within the remit of oral surgery specialists to treat malignant disease. ${ }^{14,15}$ But what is the role of biopsy and diagnosis in the primary healthcare setting? Is there a benefit to patients considering the service already provided in the secondary healthcare setting? It has already been demonstrated that it is reasonable for general dental practitioners to 
undertake biopsy of oral mucosal lesions, and to discuss the histopathology report with patients. ${ }^{38,39}$ However, what is the role of the oral surgery specialist receiving referrals for potentially malignant lesions, and performing a biopsy, with a view to passing the details onto a regional head and neck oncology service should the report describe dysplastic or malignant changes? Understandably concern arises over such practice because of the risk of delay in re-referral, diagnosis, and perhaps inaccurate biopsy technique such that a diagnosis is missed, and the need for follow-up of patients considered to be at risk of developing oral carcinoma. ${ }^{40}$ With experience and the ability of specialist practitioners to exercise clinical judgement, a biopsy service for benign mucosal lesions is entirely reasonable. There will be cases where unexpected reporting of malignant or dysplastic changes will arise and provided that redirection of the referral is not delayed, patient care should not be compromised. Continuing audit provides a means of clinical governance in this matter.

There will be situations when the care of a patient is beyond the remit of primary care and referral to the secondary care sector is essential. The ability to recognise clinical signs and to make appropriate referral will be an essential skill for those providing specialist surgical services in the primary healthcare setting. Dental infections can have potentially serious complications and judgement will need to be exercised such that patient care is not compromised. ${ }^{41-43}$ Systemic disease can also limit the care that can be provided in the primary healthcare setting. While most patients with mild to moderate systemic disease can be safely treated in the primary healthcare setting, clinical judgement of when to refer learned through training and experience will benefit patient care. ${ }^{44}$ Such clinical practice and acceptance of the differing roles of primary and secondary care surgical specialists will require mutual respect, co-operation, and acceptance of the clinical remit of clinicians from both settings. ${ }^{14,45}$

Historically in the primary healthcare setting, the NHS general dental services contract may have funded dento-alveolar surgery and oral mucosal biopsy. However, while it has been shown that patients may receive a high standard of care along with high patient satisfaction, ${ }^{17}$ the NHS remuneration system is a serious impediment to such a service. ${ }^{46}$ To provide a comprehensive service in keeping with clinical governance requirements, a review of funding is essential. Inadequate funding will lead to specialist care being increasingly provided in the private healthcare sector, reducing patient access. NHS dental care is no longer free and even with funding, Primary Care Trusts (PCTs) will possibly expect patients to contribute towards their treatment costs. Administrative costs for an oral surgery referral service are significant because of the need for separate operating and recovery areas, extra equipment, additional nursing and clerical staff, as well as on-call arrangements. Some professional indemnity and insurance providers already charge higher fees for such care. ${ }^{47,48}$ The oral surgery specialist will have made a significant investment in their own training and continuing professional development, but also in their staff. If the aspirations of the SDAC are to be achieved in increasing patient choice, and the vision of successive CDOs in increasing the provision of specialist care in the primary healthcare setting fulfilled, a review of the funding and provision of such services under NHS arrangements is essential.
A recent development by the Faculty of General Dental Practice (FGDP) has led to the title of dentist with a special interest (DwSI), one of which is minor oral surgery. The FGDP has successfully worked with the UK Department of Health in producing guidance for the contracting of DwSIs. ${ }^{49}$ The clinical remit of this group is similar to the core competencies of oral surgery, and with PCTs now having responsibility for providing specialist services, there are now additional opportunities to move specialist dental care into the high street setting. ${ }^{50} \mathrm{How}-$ ever, the Department of Health in outlining specialist services refers to minor oral surgery only, with no mention of a comprehensive diagnostic, advice and treatment service. Any attempt to restrict the established clinical remit of a registered specialist must be strongly resisted.

With research showing that the majority of general dental practitioners, the gate-keepers to specialist care, would make referrals to a practice-based oral surgery service, the interests of general dental practitioners and their patients must be considered..$^{51,52}$ The factors that influence referral patterns are waiting times and personal knowledge of the specialist that will provide the care, followed by ease of access for their patients, the perceived standard of care provided, and the ease with which an appointment could be made. ${ }^{53}$

\section{CONCLUSION}

While acknowledging that the demographic and clinical features of patients currently and previously treated in the secondary healthcare setting may differ from the small sample in this audit, it has been safe and effective at a clinical level to diagnose and treat a broad spectrum of patients and oral surgical problems in the primary healthcare setting.

1. UK specialist dental training: report from the Chief Dental Officer. London: NHS Executive, 1995.

2. Hospital doctors training for the future: the report of the Working Group on Specialist Medical Training. London: Department of Health, 1993.

3. EC Medical Directive 93/16/EEC. European Union, 1993. www.europa.eu.int/scadplus/leg/en/lvb/123021.htm

4. Proposals for the introduction of specialists titles and lists of dental specialists. London: General Dental Council, 1992.

5. EC Recognition Directive 78/686/EEC. European Union, 1978. www.ec.europa. eu/internal_market/qualifications/specific-sectors_en.htm \#dentists

6. EC Training Directive 78/687/EEC. European Union, 1978. www.ec.europa. eu/internal_market/qualifications/specific-sectors_en.htm\#dentists

7. The European primary and specialist dental qualifications regulations, 1998. www.opsi.gov.uk/si/si1998/98081102.htm\#10

8. Distinctive branches of dentistry. London: General Dental Council, 1998.

9. The NHS plan: a plan for investment. A plan for reform. London: Department of Health, 2000. www.doh.gov.uk/nhsplan

10. Modernising NHS dentistry - implementing the NHS plan. London: Department of Health, 2000. www.doh.gov.uk/cdo

11. NHS dentistry: options for change. London: Department of Health, 2002 www.dh.gov.uk/assetRoot/04/08/22/78/04082278.pdf

12. Standing Dental Advisory Committee. Review of the dentally based specialities and specialist lists. London: Department of Health, 2003. www.advisorybodies.doh.gov.uk/sdac/specialist-review.pdf

13. Standing Dental Advisory Committee. Review of the dentally based specialities and specialist lists. Report to the Chief Dental Officer for England of an expert group. London: Department of Health, 2004. www.advisorybodies.doh.gov. uk/sdac/specialist-review-report.pdf

14. Specialist Lists Review Group. Final report. London: General Dental Council, 2005

15. Advisory Committee on the training of Dental Practitioners. Draft competencies for two specialist categories: orthodontics and oral surgery. XV/E/8385/3/ 95-EN. www.dented.org/info/sect3.html

16. American Society of Anaesthesiologists. ASA physical status classification system. www.asahq.org/clinical/physicalstatus.htm

17. Clark $\mathrm{S}$. The patient's view of minor oral surgery in dental practice. BrDent J 1995; 179: 71-73.

18. Coulthard P, Kazakou I, Koran R, Worthington H V. Referral patterns and the referral system for oral surgery care. Part 2: the referral system and telemedicine. Br Dent J 2000; 188: 388-391. 
19. Irvine $\mathrm{GH}$, Hapangama N. Post-operative follow-up following the removal of wisdom teeth. Br Dent J 1998; 185: 565-566.

20. Oldham R, Boyles J. Post-operative review. Br Dent J 1999; 186: 210-212.

21. Jaafar N, Nor G M. The prevalence of post-extraction complications in an outpatient dental clinic in Kuala Lumpur, Malaysia - a retrospective study. Singapore Dent J 2000; 23: 24-28.

22. Lopes V, Mumenya R, Feinmann C, Harris M. Third molar surgery: an audit of the indications for surgery, post-operative complaints and patient satisfaction. Br J Oral Maxillofac Surg 1995; 33: 33-35.

23. Osbourne P T, Frederickson G, Small A I, Torgerson S T. A prospective audit of complications related to mandibular third molar surgery. J Oral Maxillofac Surg 1985; 43: 767-769.

24. Heasman $P$ A, Jacobs D J. A clinical investigation into the incidence of dry socket. Br J Oral Maxillofac Surg 1984; 22: 115-122.

25. Bergdahl M, Hedstrom L. Metronidazole for the prevention of dry socket after removal of partially impacted mandibular third molar: a randomised controlled trial. Br J Oral Maxillofac Surg 2004; 42: 555-558.

26. Laskin D M. The selection of proper gloves for intraoral surgery. J Oral Maxillofac Surg 1999; 57: 887.

27. Cheung $L K$, Chow $L K$, Tsang $M H$, Tung L K. An evaluation of complications following dental extractions using either sterile or clean gloves. Int J Oral Maxillofac Surg 2001; 30: 550-554

28. Adeyemo W L, Ogunlewe M O, Ladeinde A L, Bamgbose B O. Are sterile gloves necessary in nonsurgical dental extractions. J Oral Maxillofac Surg 2005; 63: 936-940

29. Macluskey M, Slevin M, Curran M, Nesbitt R. Indications for and anticipated difficulty of third molar surgery: a comparison between a dental hospital and a specialist high street practice. Br Dent J 2005; 199: 671-675.

30. Lawler B, Sambrook P J, Goss A N. Antibiotic prophylaxis for dentoalveolar surgery: is it indicated? Aust Dent J 2005; 50 (Suppl): 54-59.

31. Monaco G, Staffolani C, Gatto M R, Checchi L. Antibiotic therapy in impacted third molar surgery. Eur J Oral Sci 1999; 107: 437-441.

32. Larsen P E. The effect of a chlorhexidiene rinse on the incidence of alveolar osteitis following the removal of impacted mandibular third molars. J Oral Maxillofac Surg 1991; 49: 932-937.

33. Caso A, Hung LK, Beirne $O$ R. Prevention of alveolar osteitis with chlorhexidiene: a meta-analytic review. Oral Med Oral Surg Oral Pathol Oral Radiol Endod 2005. 99: 155-159

34. Rood J P, Murgatroyd J. Metronidazole in the prevention of dry socket. Br J Oral Surg 1979/1980; 17: 62-70.

35. Ritzau M, Hillerup S, Branebjerg P E, Ersbol B K. Does metronidazole prevent alveolar osteitis sicca dolorosa? A double blind, placebo controlled clinical study. Int J Oral Maxillofac Surg 1992; 21: 299-302.

36. Barclay J K. Metronidazole and dry socket: prophylactic use in mandibular third molar removal complicated by non-acute pericoronitis. NZ Dent J 1987; 83: 71-75.

37. Reekie $D$, Downes $P$, Devlin $C V$, Nixon $G M$, Devlin $H$. The prevention of dry socket with topical metronidazole in general dental practice. Br Dent J 2006; 200: 210-213.

38. Franklin $C D$, Jones A V. A survey of oral and maxillofacial pathology specimens submitted by general dental practitioners over a 30 year period. Br Dent $J 2006$; 200: 447-450.

39. Diamanti N, Duxbury A J, Ariyaratnam S, MacFarlane TV. Specialists, GDPs and patients, and their attitudes to biopsy. Br Dent J 2002; 192: 588-592.

40. Thomson PJ. Specialist opinion. Br Dent J 2006; 200: 242

41. Cousin G C. Potentially fatal oro-facial infections: five cautionary tales. J R Coll Surg Edinb 2002; 47: 585-586.

42. Pappa $H$, Jones D C. Mediastinitis from odontogenic infection. Br Dent J 2005; 198: 547-548.

43. Stubinger $S$, Leiggener $C$, Sader $R$, Kunz $C$. Intraorbital abscess: a rare complication after maxillary molar extraction. J Am Dent Assoc 2005; 136: 921-925.

44. Amado-Cuesta S, Valmaseda-Castellon E, Berini-Aytes L, Gay-Escoda C. Complications of ambulatory oral surgery in patients over 65 years of age. Med Oral 2004; 9: 253-262.

45. Shepherd J. Oral and maxillofacial surgery, oral surgery and surgical dentistry: better together. Br Dent J 1999; 186: 366-367.

46. Sadler A, Davidson M, Houpis C, Watt-Smith S. Specialist practice for minor oral surgery: a comparative audit of third molar surgery. Br Dent J 1993; 174: 273-277.

47. Dental Protection website. www.dentalprotection.org/united_kingdom

48. The Dental Defence Union website. www.the-ddu.com

49. Dentists with special interests (DwSIs). London: Department of Health, 2006. www.dh.gov.uk/assetRoot/04/13/38/57/04133857.pdf

50. Primary dental services: commissioning specialist dental services (revised version). London: Department of Health, 2005. www.dh.gov.uk/assetRoot/04/12/39/74/04123974.pdf

51. Clark S. Professional attitudes to specialisation and minor oral surgery in general dental practice. Br Dent J 1995; 179: 209-213.

52. Coulthard P, Koron R, Kazakou I, Macfarlane TV. Patterns and appropriateness of referral from general dental practice to specialist oral and maxillofacial surgical services. Br J Oral Maxillofac Surg 2000; 38: 320-325.

53. Coulthard P, Kazakou I, Koran R, Worthington H V. Referral patterns and the referral system for oral surgery care. Part 1: general dental practitioner referral patterns. Br Dent J 2000; 188: 142-145. 